\section{COLOUR CODED CARIES EXCAVATION}

In May dental technology leader Sirona is bringing a detection system onto the market that enables dentists to identify reliably, quickly and simply where caries does or does not exist: SIROInspect. This helps making the right decision in caries excavation.

The caries detection system developed by Sirona lights up caries. This means dentists can reliably, quickly and simply identify where caries is concealed while excavating. The device is easy to operate, flexibly integrated into the workflow and sets technological standards.

SIROInspect is based on Fluorescence-Aided Caries Excavation technology, known as FACE, which exploits the fluorescence characteristics of teeth. If teeth are illuminated with violet light in the spectrum of around $405 \mathrm{~nm}$, it doesn't only stimulate degradation products of caries bacteria but also healthy dentine to fluoresce. Healthy dental tissue lights up green whereas carious areas are visibly red. The triggers for the red colouring are porphyrin compounds which arise during the breakdown of hard dental substance by caries bacteria.

The attending dentist can therefore see at first glance which areas are carious and which ones are not. The SIROInspect diagnostic glasses filter short wavelengths below $500 \mathrm{~nm}$. By contrast, light components with higher wavelengths remain visible.

Call Sirona

Dental Systems

08450715040

or emailinfo@ sironadental.

co.uk.

\section{REFINED SWISS DENTAL INSTRUMENTS}

Deppeler is the leading Swiss manufacturer of an extensive array of dental instruments and an innovator in periodontology. Since 1934, Deppeler has specialised in the design and manufacture of hand-held dental instruments for use in preventive treatment, periodontology and surgery. Each new product is the subject of careful research and clinical testing to ensure that it meets customer needs closely.

Deppeler dental instruments, such as the M23 scaler, the easy-sharp sharpening system, the Cleanext handles range, and new double-sided titanium instruments, are designed, produced and manufactured by hand at its premises in Switzerland. Shape, angulation, cutting edge and weight all undergo strict quality controls, offering dental professionals a range of robust, high performance, ergonomic products. www.deppeler.ch

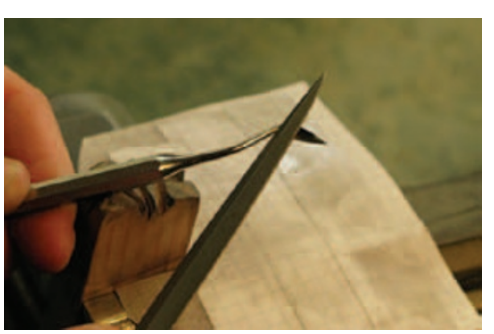

\title{
EVEN NEWLY ERUPTED MOLARS CAN BE SEALED
}

GC Fuji Triage is a command set glass-ionomer material which has been developed for fissure and root surface protection, hypersensitivity prevention and provisional treatment procedures such as intermediate endodontic sealing.

Fuji Triage has proved to be particularly useful when saliva control is not possible. Fuji Triage will bond in a damp environment without any effect on the bonding, setting or physical properties of the material. New erupted molars, even when partially covered by tissue can be sealed with Fuji Triage.

Due to the low viscosity of Fuji Triage the material is very easy to apply and being a glass ionomer has a high level of fluoride release, which is on going. The pink colour of the material is easy to detect in the back of the mouth and the translucent tooth shade is perfect when treating hypersensitivity in the anterior region. This radiopaque material has a working time of one minute and 40 seconds and a chemical cure setting time of two minutes and 30 seconds. Fuji Triage can be light cured for 20 seconds to speed up the acid-base reaction.

Both the pink and white versions of Fuji Triage are available in capsules or powder/ liquid versions to ensure that you have the choice.

For further information call GC UK on 01908218999 or email gcuk@btinternet.com.

\section{PUT A BIT OF ZEST INTO PATIENT BOOKINGS}

Zesty is a simple new way to increase your NHS and private patient bookings. Launched in London this month, Zesty is an easy to use and cost effective lead generation service driving new patients and new appointments to you and your practice.

Over a million people search for dental services online in London every month; Zesty's job is to make your dental practice visible to thousands of potential new patients in London every day.
Zesty.co.uk can help your practice by: verifying all new patient appointments by text message, making sure they are genuine before committing to the appointment in your diary; helping you to monetise your last minute cancellations and earning money on previously unused same day and next day appointments; sending appointment reminders to patients' mobile phones via SMS and Push Notifications; providing you with a free practice page to communicate your key messages to new patients looking to book an appointment online; and offering pre-made templates for location maps, staff and dental surgeon bios, practice history and price lists.

Zesty will soon be available across the UK.

Register your practice today and upload your free appointment times at www.zesty.co.uk. 